\title{
FILOSOFIA, CONSTITUINTE E SOCIEDADE BRASILEIRA
}

\author{
PHILOSOPHY, CONSTITUENT AND BRAZILIAN SOCIETY
}

Elton Vitoriano Ribeiro*

\section{Introdução}

No ano de 1987, Padre Henrique Cláudio de Lima Vaz SJ (1921-2002), participou do livro "Constituinte: mineiros em busca do equilíbrio" com uma entrevista intitulada "Que constituição a Igreja pode querer" (LIMA VAZ, 1987). Neste texto, o filósofo mineiro, em suas esclarecedoras e pertinentes observações, traça um perfil do contexto histórico-social da realidade brasileira daquela época. Esta composição de lugar apresentada pelo filósofo delineava o contexto onde a nova constituição deveria encarnar-se, com seus desafios e suas possibilidades. Como arguto filósofo que era Padre Vaz não discursou propriamente sobre a dimensão teórica da constituição, seu papel, sua estrutura e sua incidência na sociedade brasileira. Ele analisou a cultura brasileira porque, para Padre Vaz, "A constituição não é uma panaceia. (...) Sem a reforma moral dos costumes políticos brasileiros toda a constituição permanecerá letra morta e inoperante" (LIMA VAZ, 1987, p.349). Na observação de Padre Vaz o que interessa para a verdadeira efetivação da Constituição é desenvolver um ethos político para o Brasil, digno de uma nação civilizada.

Passaram-se os anos. Neste ano o Brasil comemora os 28 anos da atual Constituição que representou, sem sombra de dúvidas, um passo decisivo na construção conjunta de um horizonte democrático para a nação brasileira. Neste mesmo período, a sociedade brasileira foi aprendendo que passar da lei escrita para a lei vivida, para a efetivação da lei na vida concreta dos homens e mulheres que vivem no país, exige tempo e mobilização política da sociedade. Este processo vivido é o caminho para a concretização dos direitos que são assegurados e reconhecidos pela Constituição. Neste contexto a pergunta aqui é: possui ainda relevância as ideias apresentadas por Padre Vaz vinte e cinco anos atrás? Concretizou-se o desejo expresso por Padre Vaz no final de seu texto quando afirmou: "O destino do Brasil

\footnotetext{
* Doutorado em Filosofia pela Pontifícia Universidade Gregoriana (2010). Atualmente é professor assistente da Faculdade Jesuíta de Filosofia e Teologia.
} 
como nação-continente aponta para o século XXI com a perspectiva de uma posição-chave no contexto mundial. Esperemos que a Constituição de 1987 trace um roteiro seguro para esse caminho de grandeza, que nos possa levar a uma sociedade política livre, justa, soberana e, para usar a expressão célebre do mestre da nossa geração, Jacques Maritain, não decorativamente mas vitalmente cristã" (LIMA VAZ, 1987, p.351-352). Neste texto pretendo fazer uma releitura da obra de Padre Vaz apontando para duas questões presentes na entrevista e no parágrafo acima. Primeiro discutindo a questão da "Constituinte e a Realidade brasileira". Depois refletindo sobre a mudança das relações entre a "Constituinte e a Igreja". Assim, acredito, poderemos ainda hoje aprender com as lições deste grande mestre do pensar que foi Padre Vaz (RIBEIRO, 2011).

\section{A Constituinte e a Realidade Brasileira}

Na entrevista, ao falar sobre "A Constituinte e a Realidade Brasileira", Padre Vaz aponta como uma das tarefas mais importantes da nova constituição: "A definição de normas constitucionais básicas que permitam a adequação dos nossos avançados indicadores econômicos e dos nossos atrasados indicadores sociais" (LIMA VAZ, 1987, p.347). Completando ele afirma que a constituição deveria "estabelecer uma estrutura jurídica fundamental, sobretudo em pontos decisivos para o projeto democrático de uma nação moderna, como direitos individuais e ordem econômica e social" (LIMA VAZ, 1987, p.348).

A preocupação de Padre Vaz, ao apontar para algumas tarefas importantes, está voltada para a constituição de uma cultura de vida, um imaginário social ético onde toda a nação brasileira pudesse crescer e se desenvolver, não apenas materialmente, mas sobretudo eticamente. Ora, para Padre Vaz a questão de maior relevo na sociedade brasileira contemporânea é uma questão eminentemente ética (RIBEIRO, 2012, p.71-102). Ela se apresenta como busca das razões de viver, como busca radical do sentido da existência humana. A questão ética, portanto, se apresenta como a questão de todos nós. Desta forma, dos grandes temas da ética nenhuma inteligência pode se esquivar. Padre Vaz apresenta um pensamento que proclama a necessidade de uma reflexão sobre os fundamentos da ética como etapa necessária para a busca de soluções aos problemas éticos da humanidade. Busca essa que vai contra a pura manipulação técnica da realidade que acaba por nos deixar sem outra regra senão os fins imediatos da utilidade e da satisfação das necessidades. E que, em última 
instância, deixa ao agir humano apenas o vagar errante no espaço anônimo do niilismo, da falta de sentido.

\section{Tarefas para a filosofia política}

A pergunta que poderia aparecer agora é: o sonho de Padre Vaz para a sociedade brasileira realizou-se? A nação brasileira tornou-se cultural e socialmente avançada em sua vida moral e política? Qual é o terreno, passados estes 28 anos da constituinte, em que a Constituição brasileira deve encarnar-se hoje? Como a globalização, processo mundial e inevitável, configura este novo lugar no qual o Brasil se encontra hoje? O que o filósofo Padre Vaz teria a nos dizer sobre esta "realidade brasileira" que ele tanto estudou? Ora, comecemos com a lição de Padre Vaz sobre filosofia política.

A política é uma atividade humana orientada para o controle e o uso do poder na organização e no gerenciamento da sociedade. Ela relaciona-se com tudo aquilo que diz respeito aos cidadãos, ao governo das cidades, aos negócios públicos, ou seja, todas as relações que os seres humanos como animais políticos vivem em sociedade. Neste contexto, o filósofo deverá analisar as relações dos cidadãos entre si e com a sociedade; as formas de poder e as condições em que o poder é exercido; as constituições, os sistemas de governo; e a natureza, validade e justificação das decisões políticas. Estudará também a natureza, validade e justificação das instituições coercitivas que compõem as sociedades desde as mais elementares como a família até as mais complexas como é o caso do estado nação.

Para Padre Vaz, a política "nasce com a tarefa de desvincular o exercício do poder como força ou como violência, assumindo está tarefa na esfera legitimadora da lei e do direito" (LIMA VAZ, 1988, p.136). A partir desta tarefa, a filosofia política terá que justificar em um discurso filosoficamente coerente, isto é, racionalmente fundado, o projeto de uma existência consensual em torno do mais justo que, por definição, será também o melhor para a sociedade: “A arte da política, à luz da virtude intelectual da prudência, empenha-se na difícil e delicada tarefa de conciliar o possível com o melhor" (LIMA VAZ, 2000, p.83). A perspectiva de Padre Vaz quer compreender dialeticamente tanto a visão grega que interpretava a política como uma atividade de caráter moral, como arte da conciliação e do acordo consensual, criando um espaço racional de busca do melhor possível; quanto à compreensão moderna, mais pragmática, onde a política é entendida como lugar da razão calculadora na arte de governar, voltada por sua vez, para a conquista e a conservação do poder. 
Com estes pressupostos anteriormente descritos, o filósofo deve mirar os desafios éticos e sociais que terão grande influência sobre a vigência da Constituição e pensar racionalmente, esclarecendo desafios, elucidando argumentos e apontado saídas. No Brasil contemporâneo, globalizado e multicultural, algumas perguntas são inevitáveis (RIBEIRO, 2012a): Quais são as nossas obrigações uns para com os outros na construção de uma sociedade democrática? É possível legislar sobre moral? O mercado livre é justo? Podemos taxar os ricos para com isso ajudar os pobres? O que fazer quando parece ser errado dizer a verdade? Existe conflito entre o bem comum e os direitos individuais? Em alguns casos é justificável matar outra pessoa? A tortura é justificável em alguma circunstância? O suicídio assistido é ético? Existe o mérito moral? As preferências raciais violam os direitos individuais? É possível ser uma boa pessoa sem participar da política? Devemos pagar pelos erros de nossos predecessores? O governo deve ser moralmente neutro? Como discutir eticamente sobre o aborto e sobre o casamento entre pessoas do mesmo sexo? Estas e outras questões nos ajudam a colocar o pé na realidade cotidiana do Brasil atual.

Por outro lado, e está é a lição de Padre Vaz, o filósofo deve pensar mais, pensar além, aponta estruturas que estão subjacentes aos desafios encontrados. Ora, diante destes novos desafios facilmente percebemos que na sociedade brasileira, cada vez mais, discussões sobre a questão da dignidade humana são importantes (RIBEIRO, 2011a). Reconhecer a dignidade do outro, valorizar as diferenças reconhecendo-as não é mais uma questão opcional. Mas, para bem entendermos está discussão é necessário colocá-la em um contexto maior, a saber, no contexto das discussões sobre ética. De início, sempre é bom lembrarmos que não há ética de um indivíduo apenas. Toda ética é por sua própria natureza intersubjetiva, social. Viver a vida com os outros no mundo é parte essencial de nossa existência. Assim, a dignidade humana só será, propriamente, dignidade humana se for reconhecida pelas pessoas como algo fundamental. Somente no reconhecimento da dignidade mútua, é que será possível aos indivíduos de uma sociedade realizar concretamente a comunidade ética.

Mas é importante também deixar claro que a dignidade não é fruto de uma convenção, de um consenso ou apenas do costume de determinadas sociedades. Para Padre Vaz, ela tem sua origem e seu fundamento num estatuto ontológico do indivíduo e da comunidade que decorre da sua ordenação ao bem. O conceito de dignidade humana deverá ser a ideia reguladora, o critério julgador da efetivação ou não da Constituição brasileira hoje. Por isso, não pode existir comunidade ética sem reconhecimento por parte dos indivíduos, por mais lábil e precário, da dignidade do outro. O conceito de dignidade humana é o último elo da 
cadeia conceitual que constitui a estrutura inteligível da vida ética concretamente vivida na comunidade ética sob a égide da justiça (HERRERO, 2012).

Para Padre Vaz, por exemplo, a dignidade humana não é fruto da convenção ou do contrato social. Não é uma mera igualdade aritmética materializada em documentos de identidade que buscam operacionalizar as funções burocráticas presentes na relação entre indivíduo e estado. Não é, muito menos, uma igualdade proporcional na participação nos bens materiais produzidos pelo trabalho social. Ela é uma tarefa nunca terminada, imposta a cada indivíduo, de ser sempre mais livre para a prática do bem, e de comprometer-se na obediência sempre mais exigente aos ditames da consciência moral, no reconhecimento do outro e no empenho por uma sociedade com instituições justas concretizada em uma constituição justa. Portanto, a efetivação da dignidade humana, na vida ética de nossas sociedades, terá seu conteúdo inteligível no exercício concreto da justiça fundado no reconhecimento comum da dignidade inerente a cada membro da comunidade ética enquanto ser humano.

Neste peregrinar, a reflexão inicia-se com a questão do encontro com o outro onde, no diálogo, acontece, mas também pode não acontecer, o reconhecimento e o consenso. Reconhecimento e consenso que deverão vencer os conflitos de interesses presentes em todos os grupos humanos e construir, verdadeiramente, uma comunidade ética, contexto propício para a efetivação da Constituição. Comunidade onde, com suas normas, leis e instituições, poder-se-á tentar assegurar, no tempo e na história, sua própria existência. Essa comunidade ética, que terá determinados níveis estruturais e esferas de realização, deverá constituir uma identidade ética moral que dará à própria comunidade uma consciência moral social, análoga à consciência moral do ser humano. Mas, a plena realização da comunidade ética, só se dará na justiça, seja como virtude (no indivíduo), seja como lei (na comunidade). Será esta relação dialética da justiça, defendida por Padre Vaz, que irá permitir, verdadeiramente, a constituição da uma comunidade humana como comunidade ética na justiça, ou seja, irá permitir a plena realização da tese: "viver eticamente é viver uma vida justa". Viver uma vida justa é viver a plena valorização e realização da dignidade humana. Assim, viver uma vida justa, viver a realização da dignidade humana, só será possível dentro de uma sociedade que faça da política o lugar de concretização prática da justiça por meio de leis justas. Leis justas que deverão, necessariamente, valorizar cada ser humano como portador de direitos e deveres e de uma dignidade humana inalienável.

Fica aqui o convite de nosso filósofo, a saber, o de nos dedicarmos totalmente à plena realização da vida justa na comunidade ética como a forma mais elevada da vida humana. 
Portanto, buscar o encontro com o outro, reconhecê-lo em sua dignidade, encontrar um consenso sobre as mais variadas e complexas questões, eis o maior e mais urgente desafio à nossa comunidade brasileira que se faz cada vez mais globalizada. Desafio esse que só será vencido com uma longa, insistente e eficaz educação ética para a justiça. Educação ética que tem na atual Constituição brasileira seu porto seguro, sua bússola a indicar o caminho a seguir por esta grande nação chamada Brasil.

\section{A Constituinte e a Igreja}

Na entrevista de Padre Vaz, quando ele argumenta sobre a relação "Constituinte e Igreja", o filósofo lança uma pergunta provocadora para a época e muito mais para o momento atual: "Como separar Brasil e Igreja, como entender o Brasil sem a Igreja? (LIMA VAZ, 1987, p.349)". Aqui, evidentemente, Padre Vaz fala sobre a Igreja Católica que até o ano de 1891 fez parte do Estado e esteve presente na formação do corpo histórico da nação brasileira. Ora, a própria história, em seu astuto acontecer, deu a resposta para Padre Vaz. É verdade que nos últimos anos de vida ele foi percebendo a mudança da configuração religiosa do Brasil: o aumento das novas denominações religiosas e o crescimento do poder das bancadas religiosas no Congresso Nacional. Ao mesmo tempo, a sociedade brasileira sofre uma secularização diferente da europeia por exemplo, e mais adaptada ao nosso modo de ser. Daí que, a influência moral que a Igreja católica teve nas constituições de 34 e 46, especialmente nos campos da vida moral e da formação dos indivíduos em temas como família e educação, mudaram muito nestes últimos 25 anos. Por isso, eu penso que vale a pena refletir sobre o papel da secularização na sociedade brasileira e sua influência na vida cotidiana.

Para Padre Vaz, no Brasil atual surge, cada vez mais, um novo imaginário social secular (RIBEIRO, 2013). Este imaginário produz não apenas uma nova ordem moral para a vida social, mas uma nova consciência do divino e da vida humana quotidiana. Não é difícil imaginar um quadro imanente como lugar de realização concreta deste novo imaginário social. A perda do sentido da ideia de Deus como necessária para a ordem humana social e a redução do projeto humano à realização pessoal do indivíduo configuram parte desta virada antropológica. Esta ordem impessoal onde Deus é visto como o arquiteto do universo, atuante apenas nas leis imutáveis da natureza, ajuda a criar este clima de desencantamento. Deus ainda permanece como o criador, o maior benfeitor ao qual os seres humanos devem toda a 
gratidão. Porém, a vida quotidiana é cada vez mais marcada pelo papel crescente da economia e da racionalidade instrumental. Deus vai tornando-se uma realidade secundária. A ordem social é fruto do trabalho humano, que juntamente com a realização moral, é resultado do esforço humano que se empenha responsavelmente numa realidade concreta e imanente. Todo este movimento não poderia deixar de produzir um novo horizonte de sentido. Este novo horizonte fica a meia da estrada entre o ateísmo e o teísmo. É um espaço intermediário de uma espiritualidade indefinida e de uma nova atitude diante da moral que passa cada vez mais a aceitar os limites da condição humana descritos pela ciência.

Neste complexo processo de transformação da sociedade brasileira, a melhor forma de compreender a secularização não é a de investigar a passagem de uma cultura crente para uma cultura secular. A melhor forma é fazer atenção aos novos horizontes de compreensão da religião que vão surgindo. A secularização não significa simplesmente declínio da religião. A secularização comporta uma mudança na forma das pessoas se confrontarem com a religião. A cultura da secularização não gera necessariamente uma crise total, nem uma negação absoluta da religião. Para Padre Vaz, a sede da transcendência continua a ser presente como uma forma de religião mínima. Por isso, a religião deve caracterizar-se pela fé numa realidade transcendente e na aspiração a uma transformação que ultrapasse a mera realização humana ordinária. Assim, é possível constatar o aparecimento de novas modalidades de vivência religiosa. Novas formas de oração e meditação. O crescimento de obras de caridade. Grupos de estudo e aprofundamento da fé. Peregrinações. Modalidades diversas de grupos de partilha e vida espiritual. É a sobrevivência na religiosidade, da transcendência, numa sociedade secularizada. Este crescimento é acompanhado pelo aumenta das bancadas religiosas no Congresso Nacional, por novas interpretações das leis e costumes da nação brasileira a partir de determinados pressupostos religiosos, e porque não dizer, por um novo olhar sobre a nossa Constituição e sua efetivação na vida do povo brasileiro.

Apesar das discussões sobre o declínio da prática religiosa, a sociedade brasileira contemporânea não pode ser entendida simplesmente como irreligiosa. Na medida em que antigas formas de religiosidade vão enfraquecendo, novas formas vão surgindo e ganhando força. Estas novas formas são tentativas de viver a fé e a espiritualidade numa nova situação, onde a religião já não é algo partilhado por todos. A secularização não implica a ausência da religião ou o fim das exigências espirituais do ser humano. Implica o desenvolvimento de novos impulsos espirituais, muito mais fracionados do que no passado. Para Padre Vaz, o perigo da secularização é o de construir um imaginário social pequeno e fechado, não levando 
em consideração as questões postas ao ser humano pela religião. Isto porque, o ser humano ainda leva dentro de si um desejo de plenitude que ultrapassa a realização humana no mundo histórico. Daí novas perguntas surgem, um pouco diferentes daquelas apontadas por Padre Vaz há 25 anos. As perguntas agora deveriam caminha na direção da compreensão do papel da Constituição nesta nova configuração, muitas vezes duvidosa, da religiosidade brasileira, como fonte de influência moral nas vidas das pessoas e na sustentação moral das leis e costumes expressos na Constituição.

\section{Conclusão}

Depois desta releitura do pensamento de Padre Vaz à luz da entrevista sobre a constituinte poderíamos nos perguntar: qual o valor de toda esta reflexão aqui desenvolvida para a interpretação destes 25 anos de vida da Constituição Brasiileira?

Ora, minha inteção aqui, como eu expressei no início seguindo a intuição de Padre Vaz, foi a de ampliar os horizontes, jogar luz sobre a realidade brasileira e sobre o imaginário social que constitui, organiza e caracteriza nossa forma brasileira de agir, de decidir. Este horizonte é aquele no qual nós interpretamos nossa Constituição, podemos dizer, no qual ela se encarna. Nas palavras de Padre Vaz: "A natureza do Estado de direito não é só uma natureza políticojurídica; é também, e essencialmente, uma natureza moral, na organicidade da sua estrutura de poder legislativo, judiciário e executivo. Nesse sentido o Estado é ou deve ser a expressão mais alta e mais abrangente dos valores éticos da sociedade da qual procede" (LIMA VAZ, 1987, p.351). Ora, se a lição do mestre é de que a constituição é sempre um conjunto de lei fundamentais que são definidoras de um regime político e de uma nação, de suas instituições, da forma de governo de um estado; então nada mais própicio do que a reflexão filosófica para perceber que, como citei no início, a Constituição deve caminhar sempre junto com a reforma dos costumes políticos e da educação ética da sociedade, para, usando uma metáfora de Platão, florescer em paz iluminada pelo sol do bem e da justiça.

\section{Referências}

HERRERO, J. F. "A Ética filosófica de Henrique Cláudio de Lima Vaz". Revista Síntese, v.39, n.125, 2012, p. 393-432.

LIMA VAZ, H. C. "Que constituição a Igreja pode querer?", in: OLIVEIRA, I. Constituinte: Mineiros em busca do equilíbrio. Belo Horizonte: Lutador, 1987, p.159-167. Entrevista 
concedida a Itamar de Oliveira. Publicada também na Revista Atualização, ano XVIII, n.208, Jul/Ago 1987, p. 345-352. As referências às páginas neste artigo são as da Revista Atualização.

LIMA VAZ, H. C. Escritos de Filosofia II: Ética e Cultura. São Paulo: Loyola, 1988, p.136.

LIMA VAZ, H. C. Experiência Mística e Filosofia na Tradição Ocidental. São Paulo: Loyola, 2000, p.83.

RIBEIRO, E. V. "Uma vida a serviço da fé e da razão: Pe. Henrique Cláudio de Lima Vaz, SJ". Atualização, ano XLI, n.352, Set/Out 2011, p.433-446.

RIBEIRO, E. V. "A categoria de justiça: momento fundamental de realização da comunidade humana como comunidade ética segundo Lima Vaz", Revista de Filosofia Argumentos, Fortaleza, v.3, 2011a, p.70-78.

RIBEIRO, E. V. Reconhecimento ético e virtudes. São Paulo: Loyola, 2012, p. 71-102.

RIBEIRO, E. V. "Justiça (resenha)". Revista Síntese, Belo Horizonte, v.39, n.125, set./dez. 2012a, p. 479-484.

RIBEIRO, E. V. "Intérprete da secularização". Jornal Estado de Minas, 04/maio/2013, p.3. 